\title{
Analysis of Wellhead Uplift in Offshore Thermal Recovery by Using Finite Element Numerical Simulation
}

\author{
Shexia Dong, ${ }^{1}$ Dongsheng Zhuang, ${ }^{1}$ Gongming Ji, ${ }^{1}$ Chunming Zhu, ${ }^{1}$ and Ting Sun $\mathbb{D}^{2}$ \\ ${ }^{1}$ COSL Production Optimization Division, Tanggu, Tianjin 300451, China \\ ${ }^{2}$ China University of Petroleum, Beijing 102249, China \\ Correspondence should be addressed to Ting Sun; ting.sun@cup.edu.cn
}

Received 28 June 2017; Accepted 1 November 2017; Published 2 January 2018

Academic Editor: Yingfang Zhou

Copyright (c) 2018 Shexia Dong et al. This is an open access article distributed under the Creative Commons Attribution License, which permits unrestricted use, distribution, and reproduction in any medium, provided the original work is properly cited.

\begin{abstract}
Pilot test of complex thermal fluid recovery technology was conducted in NB35-2 heavy oil field. Wellhead uplift was detected among some oil wells, and development of offshore thermal recovery technology could be restricted by the serious safety problems behind. This paper is based on the specific operating conditions of one oil well in the trial block, and the simulation calculation of casing elongation and wellhead uplift are conducted by using finite element analysis. The total casing elongation calculated is $4.2 \mathrm{~cm}$, which is consistent with the field test results. According to the research, we concluded that the wellhead uplift is caused by upper casing elongation. $88 \%$ of the total elongation happens in the air and seawater sections. Elongation is lesser in strata and the casing string below $360 \mathrm{~m}$ can be considered as anchored.
\end{abstract}

\section{Introduction}

Pilot test of complex thermal fluid recovery technology was conducted in Bohai heavy oil filed since 2009 with significant producing progress achieved in NB block and LD block [13]. However, wellhead uplift was detected during the pilot test among many thermal injection wells. Based on field measuring, the average wellhead uplift is $4 \sim 5 \mathrm{~cm}$ with the highest reaching $24.5 \mathrm{~cm}$. As the last firewall for oil well safety, Christmas tree should be paid special attention and protected with all kinds of safety precautions. Possible consequences caused by wellhead uplift are as follows:

(1) Jet of complex thermal fluid wounding people when the weld bead of wellhead pipeline cracks due to over uplifting

(2) Oil and gas leakage caused by casing displacement and cement failure

(3) Casing hanger wrecks inside Christmas tree.

This paper presents simulation calculation of wellhead uplift-related casing elongation in the air section, seawater section, and strata section by using finite element analysis.
Issues are studied including whether the downhole string elongation is uniform, whether the cement between casings is under destruction, and what is the safety limit for uplift.

\section{Current Advances}

Numerical simulation calculation is a widely applied research method both domestic and overseas in analyzing casing stress and deformation process during thermal injection and production [2-5]. According to the investigation, the numerical study on the stress state and deformation process of casing is less abroad. The finite element method is used to analyze the wellbore, casing, and formation as a whole and to establish the wellbore and formation temperature field calculation model at home. Under ideal conditions, the bearing characteristics are analyzed under the action of uniform internal pressure, uniform ground stress, and temperature load. The method does not consider the casing state of different sections, and the error is larger. Now, domestic application of finite element analysis is operated in steps. First, take wellbore, casings, and strata as an entity and build a temperature calculation model. Then, build a stress field calculation model and analyze the stress status of steam injection string and the casing string 
in the well. Obtain stress and strain of casing string by deriving stress calculation formats of steam injection string and casing string while operating. Furthermore, based on the ideal conditions of uniform internal pressure, uniform stress, and uniform temperature load, analyze the bearing behavior of the selected study object of casing-cement sheath-strata with plane strain element PLANE183 [4, 5].

Although there is a lot of analysis on casing stress, wreck, and precautions for thermal recovery both domestic and overseas, still no integrated solution for wellhead uplift is brought up. Exploratory research on wellbore uplift in offshore thermal recovery is also under its way, most of which bases on the ideal cylinder model without casing coupling. Besides, the uplift calculation is mainly based on free elongation, which cannot accurately simulate the real structure and uplift process of thermal recovery wellbores. Limitations of existing calculation methods are as follows [6-10].

(1) Temperature field plays a decisive role in casing elongation and Christmas tree uplift. However, in present calculations for temperature field, seawater's impact on heat transfer is neglected [11]. In fact, considering the differences between land recovery and offshore recovery, seawater has a major influence on temperature distribution to the three layers of casings.

(2) In present domestic research, downhole string is always taken as an entity under uniform load and applied plane strain element [12-15], while, in this paper, 3D finite element model is built for simulation, which is unlike the present model without decoupling and sliding between casings, cement sheath, and strata. By simulating the casing stress and elongation separately in the air section, seawater section, and strata section, the new model makes sure the simulation conditions are more congruous with real work conditions and leads to more accurate results.

\section{Simulation Methods}

3.1. Simulation Ideas. (1) Based on completion string structure and offshore casing program of thermal recovery, build a finite element analysis model.

(2) Analyze radial and axial temperature distribution to casings under impacts of seawater.

(3) Based on string temperature field, simulate casing stress.

(4) By calculating elongation of all casings, obtain total wellbore uplift.

(5) Conclude regular rules of casing displacement and find the most dangerous surface by confirming the sliding critical point between different casings.

3.2. Simulation and Elongation Calculation Methods. String stress is mainly formed by interreaction between thermal field and stress field, so coupling of heat and structure in ANSYS is often applied in concrete analysis. Basic coupling method of heat and structure begins with thermal analysis and continues by loading the analysis results into structure stress analysis directly.

(1) Fill in string structure parameter list, build finite element solid model, and choose thermal analysis unit.
TABLE 1: Wellbore structure parameter.

\begin{tabular}{|c|c|c|c|}
\hline String & $\mathrm{ID} / \mathrm{mm}$ & $\mathrm{OD} / \mathrm{mm}$ & Depth/m \\
\hline $\begin{array}{l}\varnothing 88.9 \mathrm{~mm}\left(31 / 2^{\prime \prime}\right) \\
\text { Insulated tubing }\end{array}$ & 75.997 & 114.3 & - \\
\hline $\begin{array}{l}ø 244.475 \mathrm{~mm}\left(95 / 8^{\prime \prime}\right) \\
\text { Technical casing }\end{array}$ & 232.49 & 244.48 & 1768 \\
\hline $\begin{array}{l}\varnothing 339.73 \mathrm{~mm}\left(133 / 8^{\prime \prime}\right) \\
\text { Surface casing }\end{array}$ & 327.54 & 339.73 & 360 \\
\hline$\emptyset 508 \mathrm{~mm}\left(20^{\prime \prime}\right)$ Riser pipe & 495.3 & 508 & 96.2 \\
\hline
\end{tabular}

(2) Define property of different materials and apply to each solid.

(3) Conduct mesh generation by using map mesh or sweep mesh.

(4) Conduct Glue operation on contact surfaces.

(5) Define temperature boundary conditions and analyze temperature distribution.

(6) Carry on unit transformation of heat-structure.

(7) Define restrict conditions, import temperature analysis results, and load fluid and strata stress.

(8) Conduct coupling analysis of thermal and structure and analyze the calculation results.

\section{Instance Study}

4.1. Basic Conditions. Well structure instance is shown in Figure 1, wellbore structure parameter is shown in Table 1, environment parameter is shown in Table 2, and thermal injection parameter is shown in Table 3.

Based on present details, the riser pipe is $96.2 \mathrm{~m}$ long with $39 \mathrm{~m}$ in the air, $12 \mathrm{~m}$ in seawater, and $45 \mathrm{~m}$ in strata. The surface casing is $360 \mathrm{~m}$ long. Since the thermal coefficients of the air, seawater, and strata are much dissimilar which exerts relative big effects on temperature distribution to casings, elongation simulation is separately conducted in the air, seawater, and strata for more accurate results of wellhead uplift.

\subsection{Calculation of Temperature Distribution}

4.2.1. Heat Transfer of Wellbore under Seawater's Impact. Consider thermal resistance of insulated tubing, annular convection of nitrogen injection, heat transfer resistance of radiation, cement and strata heat resistance in radial direction, and consider impacts of the air, seawater, and strata in axial direction. Obtain total temperature coefficient along wellbore which is shown in Figure 2 and heat loss distribution along wellbore which is shown in Figure 3. As seen from the figures, comparatively large heat loss takes place in seawater, is lesser in the air, and is the least in strata.

4.2.2. Temperature Distribution Calculation in Seawater. The complex thermal fluid injected in this well is $270^{\circ} \mathrm{C}$ and the temperature gratitude is $3^{\circ} \mathrm{C} / 100 \mathrm{~m}$. Temperature coefficient of the insulated tubings without insulated couplings 


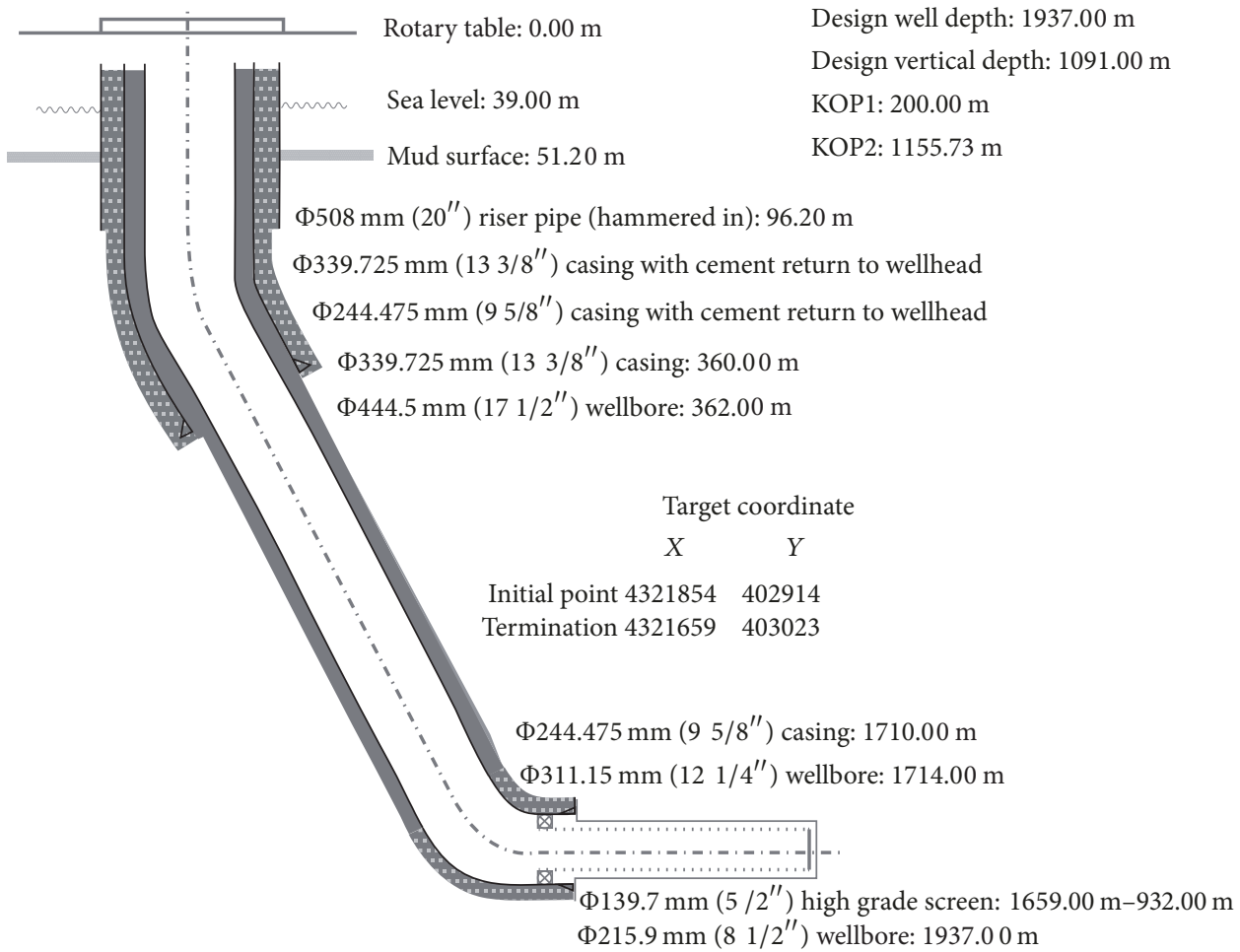

Figure 1: Well structure.

TABLE 2: Environmental parameter.

\begin{tabular}{lccc}
\hline String length in the air $/ \mathrm{m}$ & 39 & String length in seawater & 12.2 \\
Thermal coefficient of insulated tubing $/\left[\mathrm{W} \cdot\left(\mathrm{m}^{-1} \cdot \mathrm{K}^{-1}\right)\right]$ & 0.02 & Thermal coefficient of cement $/\left[\mathrm{W} \cdot\left(\mathrm{m}^{-1} \cdot \mathrm{K}^{-1}\right)\right]$ & 0.35 \\
Thermal coefficient of strata $/\left[\mathrm{W} \cdot\left(\mathrm{m}^{-1} \cdot \mathrm{K}^{-1}\right)\right]$ & 1.743 & Temperature coefficient of strata $/\left(\mathrm{m}^{2} \cdot \mathrm{s}^{-1}\right)$ & Air temperature $/{ }^{\circ} \mathrm{C}$ \\
Geothermal gratitude $/\left({ }^{\circ} \mathrm{C} \cdot \mathrm{m}^{-1}\right)$ & 0.03 & Wind speed $/\left(\mathrm{m} \cdot \mathrm{s}^{-1}\right)$ & 20 \\
Seawater temperature $/{ }^{\circ} \mathrm{C}$ & 15 & - & - \\
Seawater flow speed $/\left(\mathrm{m} \cdot \mathrm{s}^{-1}\right)$ & 0.5 & & - \\
\hline
\end{tabular}

TABLE 3: Thermal injection parameter.

\begin{tabular}{lccc}
\hline Expense of the air $/\left(\mathrm{kg} \cdot \mathrm{h}^{-1}\right)$ & 3000 & Injection temperature $/{ }^{\circ} \mathrm{C}$ & 270 \\
Expense of diesel oil $/\left(\mathrm{kg} \cdot \mathrm{h}^{-1}\right)$ & 200 & Injection pressure $/ \mathrm{MPa}$ & 18 \\
Injection rate of hot water $/\left(\mathrm{kg} \cdot \mathrm{h}^{-1}\right)$ & 8000 & Injection pressure of nitrogen $/ \mathrm{MPa}$ & 18 \\
Injection rate of all thermal fluid $/\left(\mathrm{kg} \cdot \mathrm{h}^{-1}\right)$ & 11200 & Injection rate of nitrogen $/\left(\mathrm{Nm}^{3} \cdot \mathrm{h}^{-1}\right)$ & 500 \\
\hline
\end{tabular}

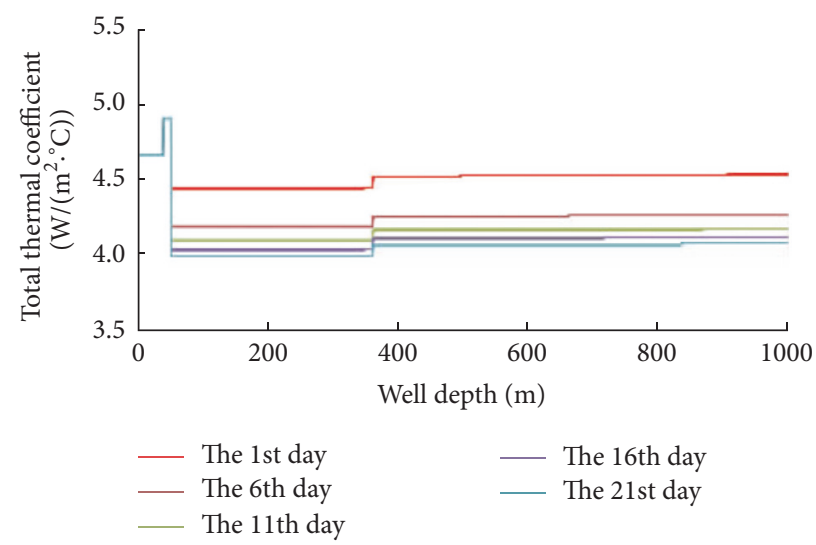

FIGURE 2: Total thermal coefficient along wellbore. 
TABLE 4: Radial temperature distribution to the completion string.

\begin{tabular}{|c|c|c|c|c|c|c|}
\hline Depth/m & $\begin{array}{c}\text { Fluid } \\
\text { temperature } /{ }^{\circ} \mathrm{C}\end{array}$ & $\begin{array}{c}ø 244.475 \mathrm{~mm}(9 \\
\left.5 / 8^{\prime \prime}\right) \text { casing } \\
\text { temperature } /{ }^{\circ} \mathrm{C} \\
\end{array}$ & $\begin{array}{l}\text { Cement boundary } \\
\text { temperature } /{ }^{\circ} \mathrm{C}\end{array}$ & $\begin{array}{c}ø 399.725 \mathrm{~mm}(13 \\
\left.3 / 8^{\prime \prime}\right) \text { casing } \\
\text { temperature } /{ }^{\circ} \mathrm{C}\end{array}$ & $\begin{array}{c}\text { Cement sheath } \\
\text { boundary } \\
\text { temperature } /{ }^{\circ} \mathrm{C}\end{array}$ & $\begin{array}{c}\varnothing 508 \mathrm{~mm}\left(20^{\prime \prime}\right) \\
\text { pipe } \\
\text { temperature } /{ }^{\circ} \mathrm{C}\end{array}$ \\
\hline 0 & 270 & 119.56 & 82.43 & 82.43 & 34.57 & 34.57 \\
\hline 10 & 269.84 & 119.5 & 82.39 & 82.39 & 34.56 & 34.56 \\
\hline 20 & 269.68 & 119.43 & 82.35 & 82.35 & 34.55 & 34.55 \\
\hline 30 & 269.51 & 119.36 & 82.3 & 82.3 & 34.54 & 34.54 \\
\hline 40 & 269.34 & 106.13 & 66.39 & 66.39 & 15.18 & 15.18 \\
\hline 50 & 269.17 & 106.06 & 66.36 & 66.36 & 15.18 & 15.18 \\
\hline 60 & 269.02 & 141.45 & 109.32 & 109.32 & 67.91 & 67.91 \\
\hline 70 & 268.87 & 141.53 & 109.46 & 109.46 & 68.12 & 68.12 \\
\hline 80 & 268.72 & 141.62 & 109.6 & 109.6 & 68.33 & 68.33 \\
\hline 90 & 268.58 & 141.7 & 109.74 & 109.74 & 68.54 & 68.54 \\
\hline 100 & 268.43 & 141.79 & 109.88 & 109.88 & & \\
\hline 190 & 267.12 & 142.54 & 111.14 & 111.14 & & \\
\hline 280 & 265.82 & 143.29 & 112.39 & 112.39 & & \\
\hline 360 & 264.66 & 143.96 & 113.51 & 113.51 & & \\
\hline
\end{tabular}

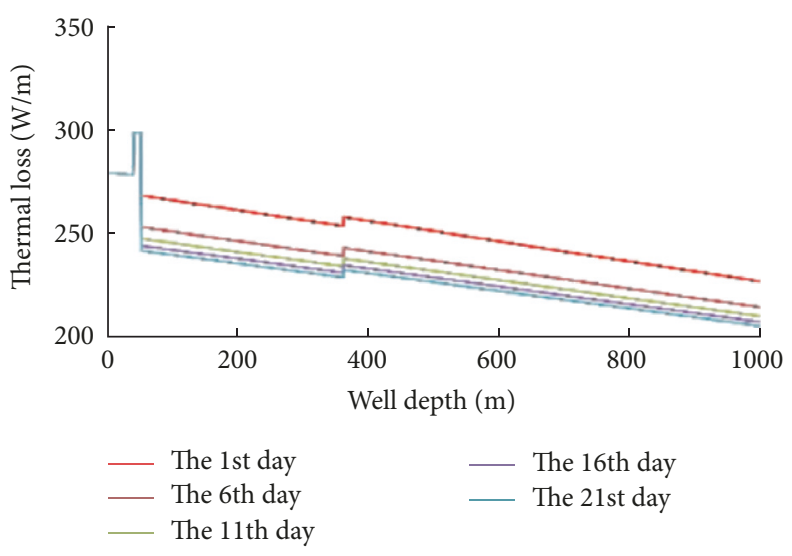

Figure 3: Thermal loss along wellbore.

is $0.12 \mathrm{~W} /(\mathrm{m} \cdot \mathrm{K})$. Based on heat transfer calculation, temperature distribution is shown in Table 4 including the $ø 244.475 \mathrm{~mm}\left(95 / 8^{\prime \prime}\right)$ casings, the 1st cement sheath, the $ø 399.725 \mathrm{~mm}\left(133 / 8^{\prime \prime}\right)$ casings, the $2 \mathrm{rd}$ cement sheath, and the $ø 508 \mathrm{~mm}\left(20^{\prime \prime}\right)$ casings.

\subsection{Stress Distribution to All Casings}

4.3.1. Meshing. Take Glue operation to simulate the surface bond state of cement and casings. Build a model of riser pipe-surface casing-production casing. The diameter is $\varnothing 244.475 \mathrm{~mm}\left(95 / 8^{\prime \prime}\right)$ for the production casing, $ø 399.725 \mathrm{~mm}\left(133 / 8^{\prime \prime}\right)$ for the surface casing, and ø508 $\mathrm{mm}$ $\left(20^{\prime \prime}\right)$ for the riser pipe. Glue the contact surfaces. Choose element brick 8 node 70 which is a hexahedron element with 8 nodes. It transfers heat in three dimensions with each node having only one temperature DOF. It is used for 3D heat analysis in both static and momentary state and is able to realize uniform heat current. A solid structure of element brick 8 node 45 can be transferred from this element for relevant structure analysis. Conduct sweep mesh generation, respectively, for each part of the wellbore. Meshing results are shown in Figure 4. Obtain temperature distribution results based on analysis of complex thermal fluid and define temperature boundary conditions for all casings.

4.3.2. Casing Elongation Simulation. Based on the previous temperature distribution analysis, conduct heat-structure coupled analysis. In order to facilitate the calculation, divide the downhole string into the air and seawater section (0 $51.2 \mathrm{~m})$, strata section $1(51.2 \sim 96.2 \mathrm{~m})$, strata section $2(96.2 \sim$ $360 \mathrm{~m})$, and strata section $3(360 \sim 1710 \mathrm{~m})$. The elongation analysis results of all 4 sections are shown in Figures 5 6.

As shown in Figure 5, the largest integral axial casing elongation in the air and seawater section $(0 \sim 51.2 \mathrm{~m})$ is $37.89 \mathrm{~mm}$.

As shown in Figure 6(a), the largest integral axial casing elongation in strata section $1(51.2 \sim 96.2 \mathrm{~m})$ is $3.55 \mathrm{~mm}$. 


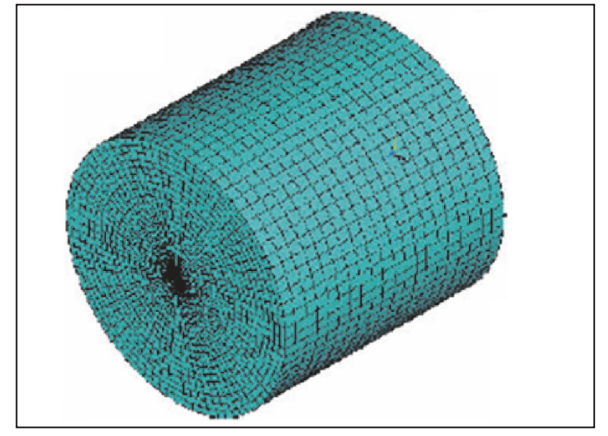

FIGURE 4: Sweep meshing of wellbore.

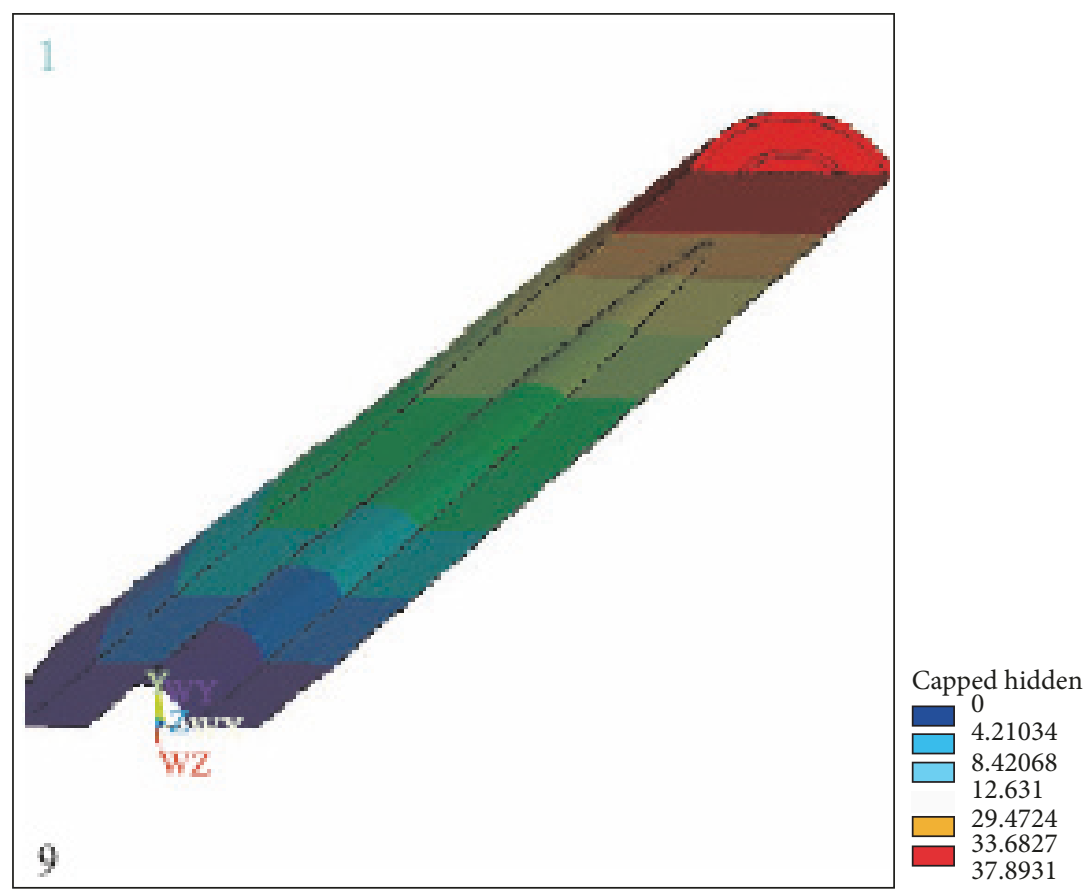

FIgURE 5: Axial casing elongation in the air and seawater section (0 51.2 m).

As shown in Figure 6(b), the largest integral axial casing elongation in strata section $2(96.2 \sim 360 \mathrm{~m})$ is $0.368 \mathrm{~mm}$.

As shown in Figure 6(c), the largest integral axial casing elongation in strata section $3(360 \sim 1710 \mathrm{~m})$ is $0.003 \mathrm{~mm}$, which is almost neglected. The thermal expansion can be considered expansion at an end, so this section is considered to be anchored.

From the above simulation, the total string $(0 \sim 1710 \mathrm{~m})$ elongation is $4.281 \mathrm{~cm}$, which is highly congruous with the field measuring result of wellhead uplift of $4 \sim 5 \mathrm{~cm}$ during heat injection process.

In summary, the elongation of the air water column is about $95 \%$ of the total elongation. The elongation of the casing in the stratum is small, and the casing string below $360 \mathrm{~m}$ can be regarded as anchor. The analysis shows that the formation has a greater binding force on the casing string, which limits the elongation of the casing string.

\section{Innovation and Conclusions}

(1) 3D finite element model is built for simulation, which is unlike the present model without decoupling and sliding between casings, cement sheath, and strata. By simulating the casing stress and elongation separately in the air section, seawater section, and strata section, the new model makes sure the simulation conditions are more congruous with real work conditions and leads to more accurate results.

(2) The wellhead uplift is caused by upper casing elongation. $88 \%$ of the total elongation happens in the air and seawater sections. Elongation is lesser in strata and the casing string below $360 \mathrm{~m}$ can be considered as anchored. It is believed from this research that strata have relative larger binding force to the string which restricts elongation.

(3) It is suggested that simulation calculation for more wells should be conducted, and on the same time, simulation tests should be run to further testify conformity between 


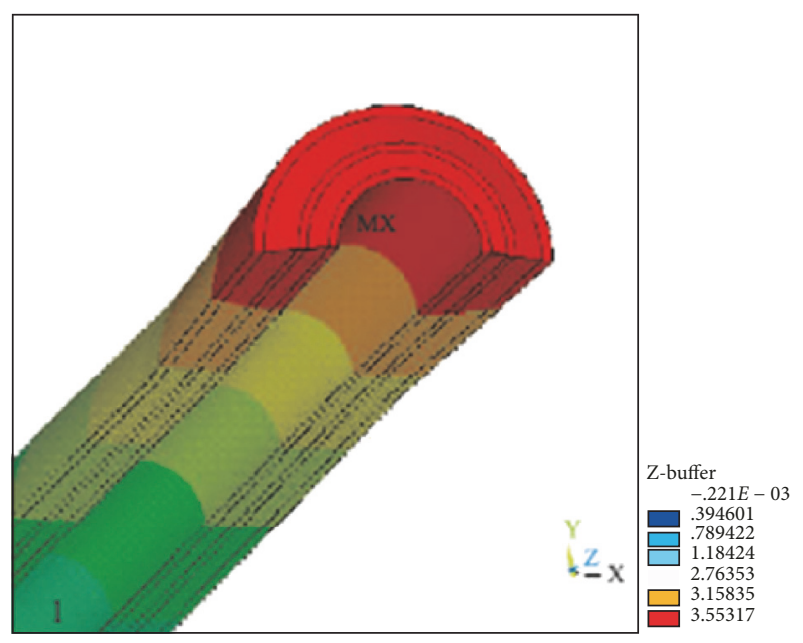

(a) Axial casing elongation in strata section 1 (51.2 96.2 m)

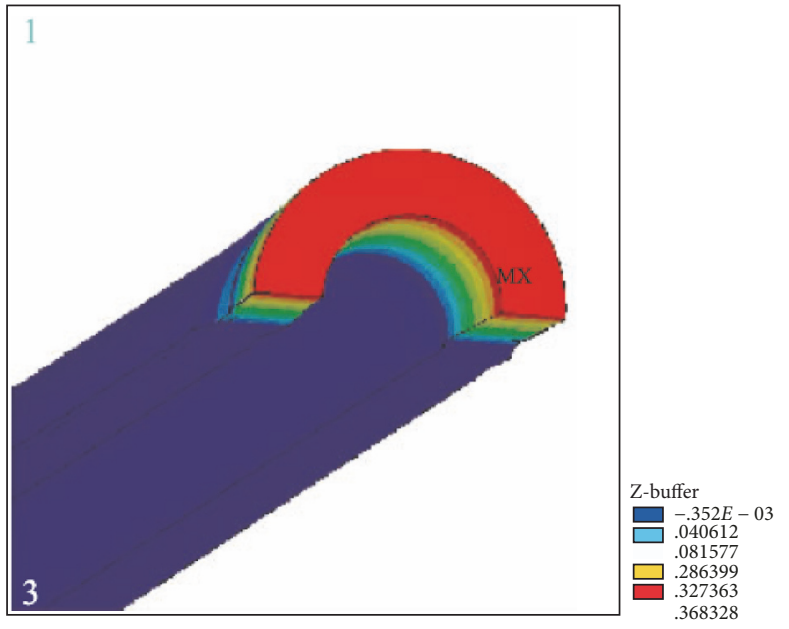

(b) Axial casing elongation in strata section $2(96.2 \sim 360 \mathrm{~m})$

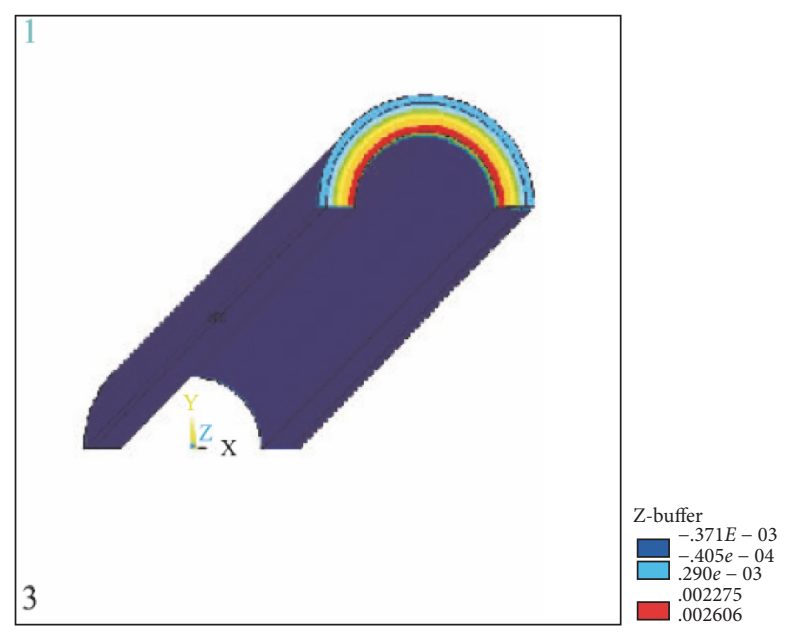

(c) Axial casing elongation in strata section $3(360 \sim 1710 \mathrm{~m})$

FIgURE 6: Axial casing elongation in different strata section.

calculation and field measuring. Moreover, by constant modification, it is suggested that wellhead uplift prediction software should be developed to provide guidance for new well thermal injection and by continuously researching on precautions, wellhead uplift will be relieved or diminished and safe thermal recovery will be realized.

\section{Conflicts of Interest}

The authors declare that they have no conflicts of interest.

\section{References}

[1] X. X. Tang, Y. Ma, and Y. T. Sun, "Completion technology and field test of complex thermal fluid stimulation for offshore heavy oil," China Offshore Oil and Gas, vol. 23, no. 3, pp. 185-188, 2011.

[2] S. Liu, H. Zheng, X. Zhu, and H. Tong, "Equations to calculate collapse strength of defective casing for steam injection wells," Engineering Failure Analysis, vol. 42, pp. 240-251, 2014.

[3] X. H. Zhu, R. Q. Sun, and H. Tong, "Research on a probabilistic assessment method based on defective casing safety evaluation criteria in thermal recovery wells," Proceedings of the Institution of Mechanical Engineers, Part C: Journal of Mechanical Engineering Science, vol. 228, no. 18, pp. 3462-3470, 2014.

[4] X. B. Cui, L. Cao, and H. Zhang, "Research of casing deformation in steam injection thermal recovery well," Petroleum University Journal, vol. 21, no. 3, pp. 57-64, 1997.

[5] H. Tong, D. Guo, and X. Zhu, "Application of multiphysics coupling FEM on open wellbore shrinkage and casing remaining strength in an incomplete borehole in deep salt formation," Mathematical Problems in Engineering, vol. 2015, Article ID 575492, 9 pages, 2015.

[6] W. Wei, L. Han, H. Wang et al., "Low-cycle fatigue behavior and fracture mechanism of hs80h steel at different strain amplitudes and mean strains," Journal of Materials Engineering and Performance, vol. 26, no. 4, pp. 1717-1725, 2017.

[7] Z. F. Li, D. H. Wu, and Y. F. Huang, "Elasticity analysis of casing string and steam injection string," Oil Drilling \& Production Technology, vol. 6, no. 17, pp. 62-63, 1995.

[8] W. Z. Liu, Steam Injection Heavy Oil Recovery Engineering, Petroleum Industry Press, Beijing, China, 1996. 
[9] J. William Carey, R. Svec, R. Grigg, J. Zhang, and W. Crow, "Experimental investigation of wellbore integrity and $\mathrm{CO} 2-$ brine flow along the casing-cement microannulus," International Journal of Greenhouse Gas Control, vol. 4, no. 2, pp. 272282, 2010.

[10] W. Wu, N. B. Dave, G. Yu et al., "Network analysis of temporal effects of intermittent and sustained hypoxia on rat lungs," Physiological Genomics, vol. 36, no. 1, pp. 24-34, 2008.

[11] X. C. Song, H. S. Zhao, and Z. C. Guan, "Analysis of casing prestress in thermal recovery," Oil Drilling \& Production Technology, vol. 28, no. 4, pp. 64-67, 2006.

[12] W. C. Li, T. Qi, and H. X. Guan, "Model research of wellbore temperature field and application in offshore thermal recovery," Southwest Petroleum University Journal, vol. 34, no. 6, pp. 105110, 2012.

[13] S. Griston and G. P. Willhite, "Numerical model for evaluating concentric steam injection wells," SPE, vol. 16337, 1987.

[14] X. S. Gao, L. X. Zhang, and N. Z. He, "Numerical simulation analysis of thermal recovery wellbore stress," Petroleum University Journal, vol. 25, no. 2, pp. 65-66, 2001.

[15] F. Qian and D. Gao, "A mechanical model for predicting casing creep load in high temperature wells," Journal of Natural Gas Science and Engineering, vol. 3, no. 3, pp. 530-535, 2011. 


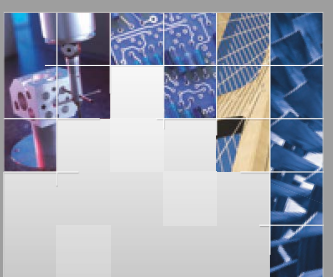

\section{Enfincering}
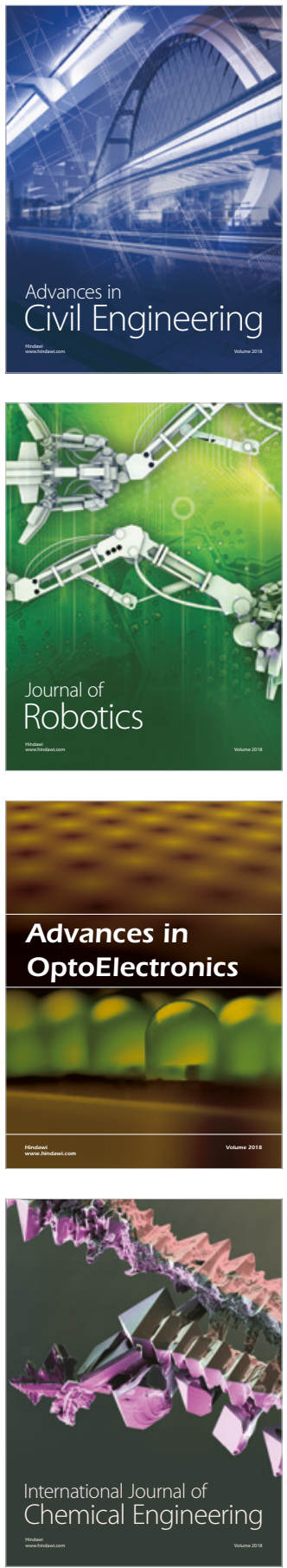

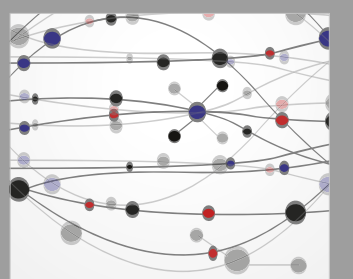

\section{Rotating \\ Machinery}

The Scientific World Journal

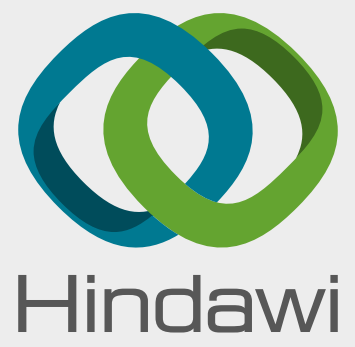

Submit your manuscripts at

www.hindawi.com
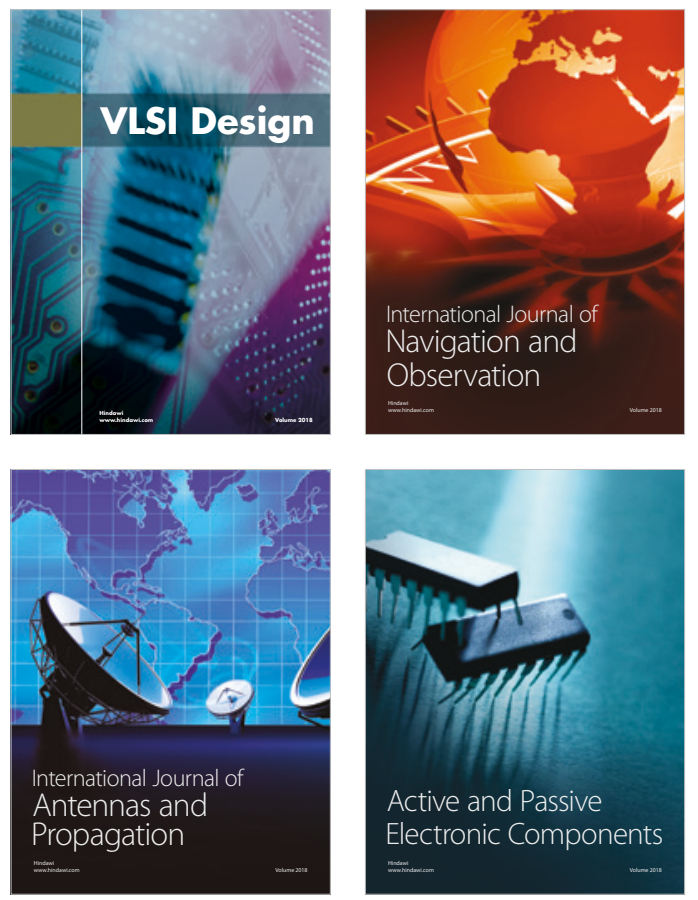
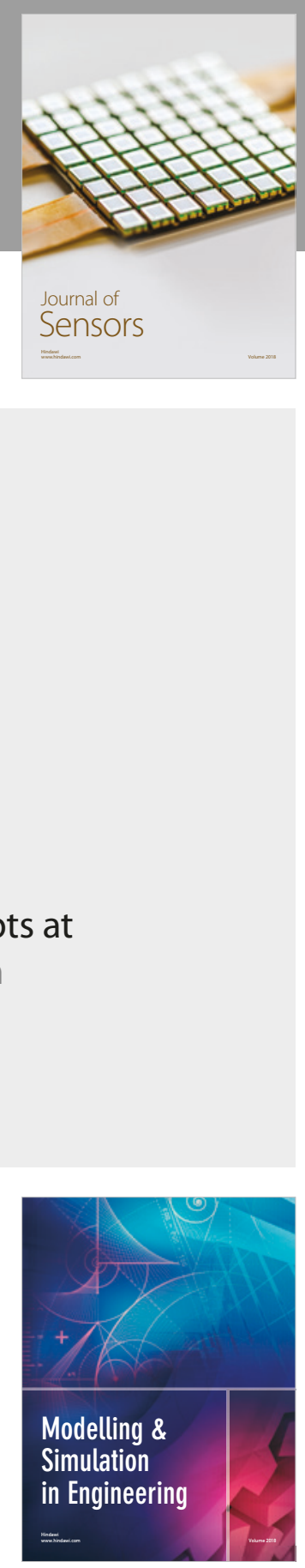

\section{Advances \\ Multimedia}
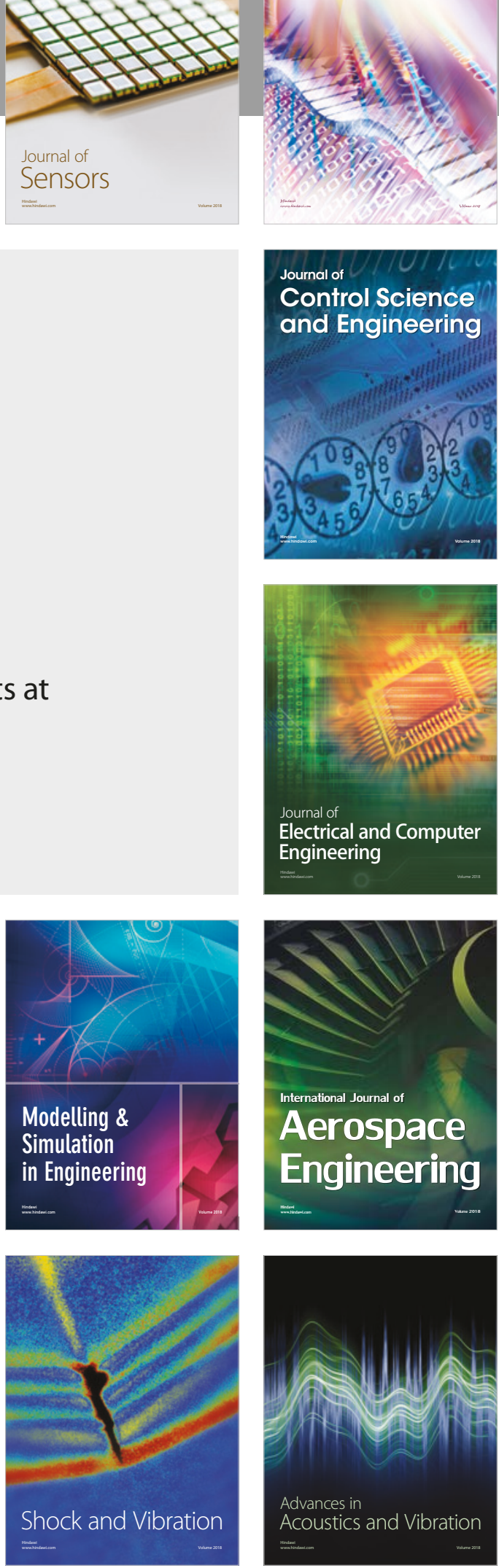